\title{
Vulnerabilidade Natural do Solo de Silveira Martins-RS
}

\author{
Franciele Francisca Marmentini Rovani ${ }^{1}$, Márcio Viera ${ }^{1}$ \\ ${ }^{1}$ Universidade Federal de Santa Maria - UFSM, Silveira Martins/RS, Brasil
}

\begin{abstract}
RESUMO
A análise ambiental, com base nos processos de morfogênese e pedogênese, possibilita informações importantes para a elaboração de políticas públicas visando o uso e ocupação da paisagem de maneira sustentável. Com isso, objetivou-se identificar os diferentes níveis de vulnerabilidade natural à perda de solo do município de Silveira Martins, RS. Foi elaborado um banco de dados espaciais em um ambiente de Sistemas de Informações Geográficas (SIG) com auxílio do software Spring. O zoneamento da vulnerabilidade natural à perda de solo foi elaborado com base nas informações referentes à declividade, geomorfologia, geologia e solos de acordo com o grau de vulnerabilidade de cada informação, por meio da álgebra de mapas. Para o território municipal de Silveira Martins identificou-se a ocorrência de cinco classes. Destacam-se as unidades estáveis com predomínio dos processos formadores do solo $(38,08 \%$ da área municipal), e as unidades moderadamente vulneráveis, prevalecendo os processos erosivos (53,67\%). As áreas classificadas como moderadamente vulnerável e vulnerável (8,25\%), correspondem a áreas com inclinações superiores a $25^{\circ}$ e com formação geológica e geomorfológica menos estáveis. Nas unidades em que predominou a vulnerabilidade natural, sugere-se especial atenção em relação ao meio natural e aos agentes que o influenciam, visando boas práticas sociais associadas às políticas ambientais no processo de tomada de decisões econômicas, possibilitando a valorização e proteção do meio natural.
\end{abstract}

Palavras-chave: diagnóstico ambiental, zoneamento ecológico-econômico, geotecnologias.

\section{Natural Soil Vulnerability of Silveira Martins-RS}

\begin{abstract}
The environmental analysis, based on morphogenesis and pedogenesis processes, provide important data for the development public policies for the use and occupation landscape sustainably. This research aimed to analyse the vulnerability to natural soil loss of Silveira Martins-RS. Therefore, created a spacial database in a Geographic Information System (GIS) using Spring software. Vulnerability to natural soil loss map was prepared based on information regarding the slope, geomorphology, geology and soils according to the degree of vulnerability of each information through map algebra. Were identified the occurrence of five classes in Silveira Martins municipality, there are the stable units with a predominance of soil forming processes (38.08\%), and moderately vulnerable units, prevailing erosion processes (53.67\%). Areas classified as moderately vulnerable and vulnerable (8.25\%) correspond to areas with slopes greater than $25^{\circ}$ and with geological and geomorphological formation less stable. The units in which predominated the natural vulnerability, it is suggested that special attention in relation to the natural environmental and the agents that influence. Thus, it is necessary to use good social practices associated with environmental policies in the process of economic decision, enabling the recovery and protection of the natural environment.
\end{abstract}

Keywords: environmental diagnostic, ecological-economic zoning, geotethnology. 


\section{INTRODUÇÃO}

As questões ambientais tornaram-se objetos de estudo de muitas pesquisas de planejamento e ordenamento territorial proporcionando discussões na sociedade, devido, principalmente à realidade das condições ambientais e da qualidade de vida das pessoas (Rovani et al., 2015). Com o crescimento populacional e consequente desenvolvimento acelerado do processo produtivo, os recursos naturais passaram a ser explorados com maior intensidade (Santos \& Sobreira, 2008b; Pereira et al., 2011; Rovani et al., 2014). Por isso, surgiram preocupações referentes à problemática do equilíbrio ambiental, da conservação e preservação dos ambientes naturais e de seu manejo sustentável.

Desta maneira, os estudos sobre o meio ambiente, com o objetivo de compreender as relações entre a sociedade e a natureza de forma integradora, precisam se preocupar não somente no levantamento de problemas ambientais causados pela sociedade e como recuperá-los, mas também, no estudo do grau de fragilidade dos diversos ambientes às interferências antrópicas (Lima \& Martinelli, 2008).

No sentido de tornar compatível o desenvolvimento econômico-social com a preservação da qualidade do meio ambiente e do equilíbrio ecológico, destaca-se uma preocupação de âmbito nacional, inerente à Política Nacional do Meio Ambiente (PNMA), estabelecendo os zoneamentos como um de seus instrumentos. O Zoneamento Ecológico-Econômico (ZEE) é um instrumento de planejamento e ordenamento territorial que busca a sustentabilidade ecológica, econômica e social, dividindo o território em zonas, de acordo com as necessidades de proteção, conservação, recuperação dos recursos naturais e do desenvolvimento sustentável (Santos \& Sobreira, 2008b; Santos \& Ranieri, 2013; Rovani et al., 2014).

O ZEE apresenta informações sobre o território necessárias para planejar a sua ocupação racional e o uso sustentável dos recursos naturais, integradas em uma base geográfica de dados (Campagnani \& Santos, 1998). Além disso, é possível identificar áreas do território, segundo potencialidades e vulnerabilidades, fundamentais para o processo de compreensão do cenário atual, integrando políticas públicas e colaborando para o processo de tomada de decisões para ordenamento do território (Santos \& Sobreira, 2008a; Lima et al., 2011; Pereira et al., 2011).

A vulnerabilidade natural, parte integrante do zoneamento, baseada no princípio da ecodinâmica de Tricart (1977), considera os processos de morfogênese e pedogênese a partir da análise integrada dos dados de solo, rochas, da vegetação e relevo (Becker \& Egler, 1996). Simões et al. (1999 p. 4) salienta que “[...] o conhecimento da vulnerabilidade natural é fundamental para prever o comportamento futuro dos sistemas naturais diante do processo de ocupação e adensamento da atividade social".

Nesta perspectiva, destaca-se o município de Silveira Martins, localizado na Região da Quarta Colônia de Imigração Italiana do Rio Grande dos Sul, como uma área importante para o desenvolvimento social e ambiental. Desde forma, esta pesquisa teve como objetivo identificar e diagnosticar a vulnerabilidade natural à perda de solo, com base nas potencialidades e fragilidades do ambiente, visando fornecer subsídios para o planejamento e gestão ambiental e econômica, em bases sustentáveis.

\section{MATERIAL E MÉTODOS}

\subsection{Caracterização da área de estudo}

O município de Silveira Martins está localizado na Quarta Colônia de Imigração Italiana, na região central do estado do Rio Grande do Sul. Encontra-se na transição geomorfológica entre a Depressão Periférica e o Planalto da Serra Geral, entre os Biomas Mata Atlântica e Pampa. A quarta colônia, constituída por nove municípios com área total de $4.850 \mathrm{~km}^{2}$ (Figura 1), é uma região caracterizada especialmente pela imigração de colonizadores italianos e alemães.

O município de Silveira Martins possui área total de $118,42 \mathrm{~km}^{2}$ e 2.449 habitantes, sendo que destes 1.091 residem na zona urbana e 1.358 na zona rural (IBGE, 2014). Predominam as atividades agropecuárias, com a presença das lavouras temporárias de milho, soja e feijão, totalizando $91 \%$ das áreas cultivadas (IBGE, 2006).

\subsection{Metodologia de estudo}

Para o desenvolvimento desta pesquisa foi usada a base cartográfica do Município, elaborada com os dados georreferenciados da base cartográfica vetorial contínua 


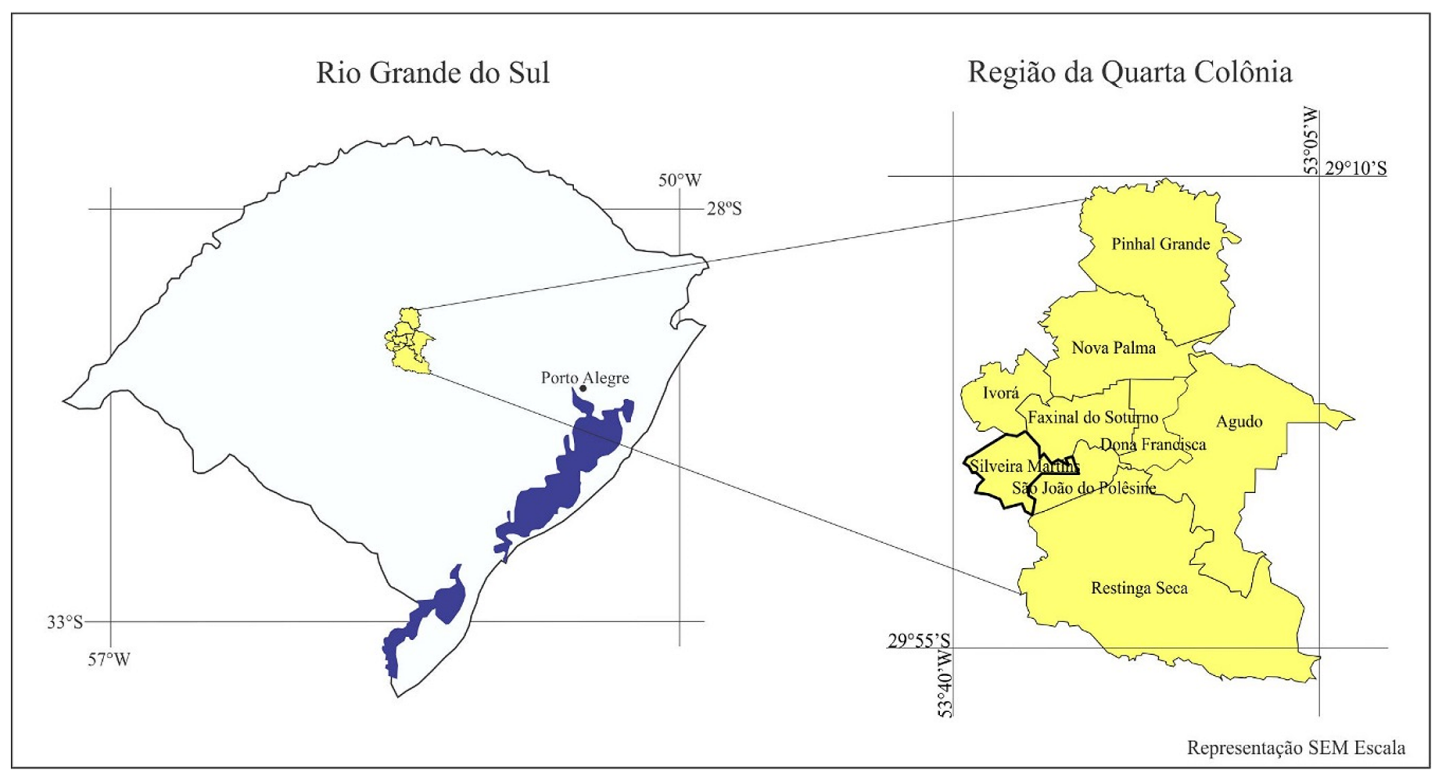

Figura 1. Localização do município de Silveira Martins.

Figure 1. Silveira Martins localization.

do Rio Grande do Sul, na escala 1/50000, organizados por Hasenack \& Weber (2010). Na construção da base cartográfica foram utilizadas duas cartas topográficas na escala 1:50000, disponibilizadas pela $1^{\text {a }}$ Divisão de Levantamento ( $\left.1^{\text {a }} \mathrm{DL}\right)$, que compreendem o território municipal: Camobi MI - 2965/2 e Faxinal do Soturno MI - 2966/1.

Utilizou-se os mapas temáticos de Geologia (IBGE, 2003a) e Geomorfologia (IBGE, 2003b) obtidos junto ao Instituto Brasileiro de Geografia e Estatística (IBGE) na escala 1:250000, Folha Erechim/Lages SG.22-Y-D/Z-C. O mapa de solos foi obtido do livro "Solos do Rio Grande do Sul" (Streck et al., 2008). Foi utilizada uma imagem orbital sem correção geométrica do satélite Landsat 8 (bandas 4, 5, 6 e 8), sensor OLI/TIRS, órbita 223/80, data da passagem 12 de junho de 2014. As bandas 4, 5 e 6 (multiespectrais) com resolução espacial de $30 \mathrm{~m}$ e a banda 8 (pancromática) com resolução de $15 \mathrm{~m}$. Realizou-se a fusão das bandas 4,5 e $6 \mathrm{com}$ a banda 8 , resultando uma imagem com resolução espacial de 15 m. O método utilizado para a fusão das bandas consistiu da transformação RGB para IHS (Intensidade, Matiz e Saturação). Primeiramente as bandas 4, 5 e 6 foram transformadas do sistema RGB para IHS. Posteriormente a banda pancromátrica foi transformada do sistema IHS para RGB, na imagem de intensidade juntamente com as bandas de matiz e saturação já transformadas anteriormente.

Para o processamento das informações foram utilizados os seguintes softwares: Spring versão 5.0.6, para a elaboração do banco de dados geográficos e edição; CorelDRAW X6, para a edição final dos mapas temáticos; Microsoft Ofice Excel 2007, para compilação de dados em gráficos e tabelas; um GPS (Global Positioning System) Garmim, para coleta dos dados a campo e uma câmera fotográfica, para registro dos dados verificados a campo.

$\mathrm{Na}$ análise da vulnerabilidade natural à perda de solo observou-se a metodologia proposta por Crepani et al. (1996, 2008), que propõe inicialmente a delimitação de Unidades Territoriais Básicas (UTBs) da área de estudo com base na imagem de satélite. Posteriormente foram elaborados os mapas temáticos de solos, geomorfologia, geologia e declividade. Estas informações foram integradas no banco de dados do SIG. Posteriormente foi efetuada a integração dos dados por meio da álgebra de mapas, visando a obtenção do mapa síntese das informações, como resultado final.

Os mapas temáticos pré-existentes de solos, geologia e geomorfologia foram digitalizados manualmente no Spring. Para o mapa de geomorfologia, as classes foram editadas e classificadas de acordo com as características 
do relevo verificadas com auxílio da imagem de satélite e in loco. O mapa temático de declividade foi obtido com base nas cartas topográficas e a partir do modelo numérico do terreno.

O mapa de vulnerabilidade natural à perda de solo foi elaborado a partir da integração das classes de solos, geomorfologia, geologia e declividade. A metodologia propõe uma classificação do grau de estabilidade ou vulnerabilidade (resistência ao processo natural à erosão), segundo as relações de morfogênese e pedogênese, a partir da análise integrada das rochas, do solo e do relevo. Desse modo, quando predomina a morfogênese, prevalecem os processos erosivos modificadores da forma do relevo, e, quando predomina a pedogênese, prevalecem os processos formadores do solo. A vulnerabilidade foi expressa pela atribuição de valores de estabilidade ou vulnerabilidade em uma escala de 1 a 3 (Tabela 1).

As classes de cada mapa temático foram substituídas pelos valores de vulnerabilidade preestabelecidos no SIG. Em seguida, por meio de operações de álgebra de mapas utilizando a linguagem de programação do software Spring, os atributos de cada mapa foram integrados, apresentando como resultado final um mapa síntese da vulnerabilidade natural à perda de solo do território de Silveira Martins-RS.

\section{RESULTADOS E DISCUSSÃO}

A maior parte territorial de Silveira Martins possui declividade menor que $25^{\circ}(89,8 \%)$ não havendo restrição de uso nas áreas consolidadas (Figura 2, Tabela 2). Entretanto, áreas com inclinação entre $25^{\circ}$ e $45^{\circ}$

Tabela 1. Avaliação da estabilidade/vulnerabilidade de acordo com a relação pedogênese/morfogênese.

Table 1. Stability/vulnerability assessment according to pedogenesis/morphogenesis relationship.

\begin{tabular}{clc} 
Unidade & \multicolumn{1}{c}{$\begin{array}{c}\text { Relação pedogênese/ } \\
\text { morfogênese }\end{array}$} & Valor \\
\hline Estável & Prevalece a pedogênese & 1,0 \\
Intermediária & $\begin{array}{l}\text { Equilíbrio entre a pedogênese e } \\
\text { a morfogênese }\end{array}$ & 2,0 \\
\hline Instável & Prevalece a morfogênese & 3,0 \\
\hline
\end{tabular}

Fonte: Crepani et al. (1996), modificada de Tricart (1977).

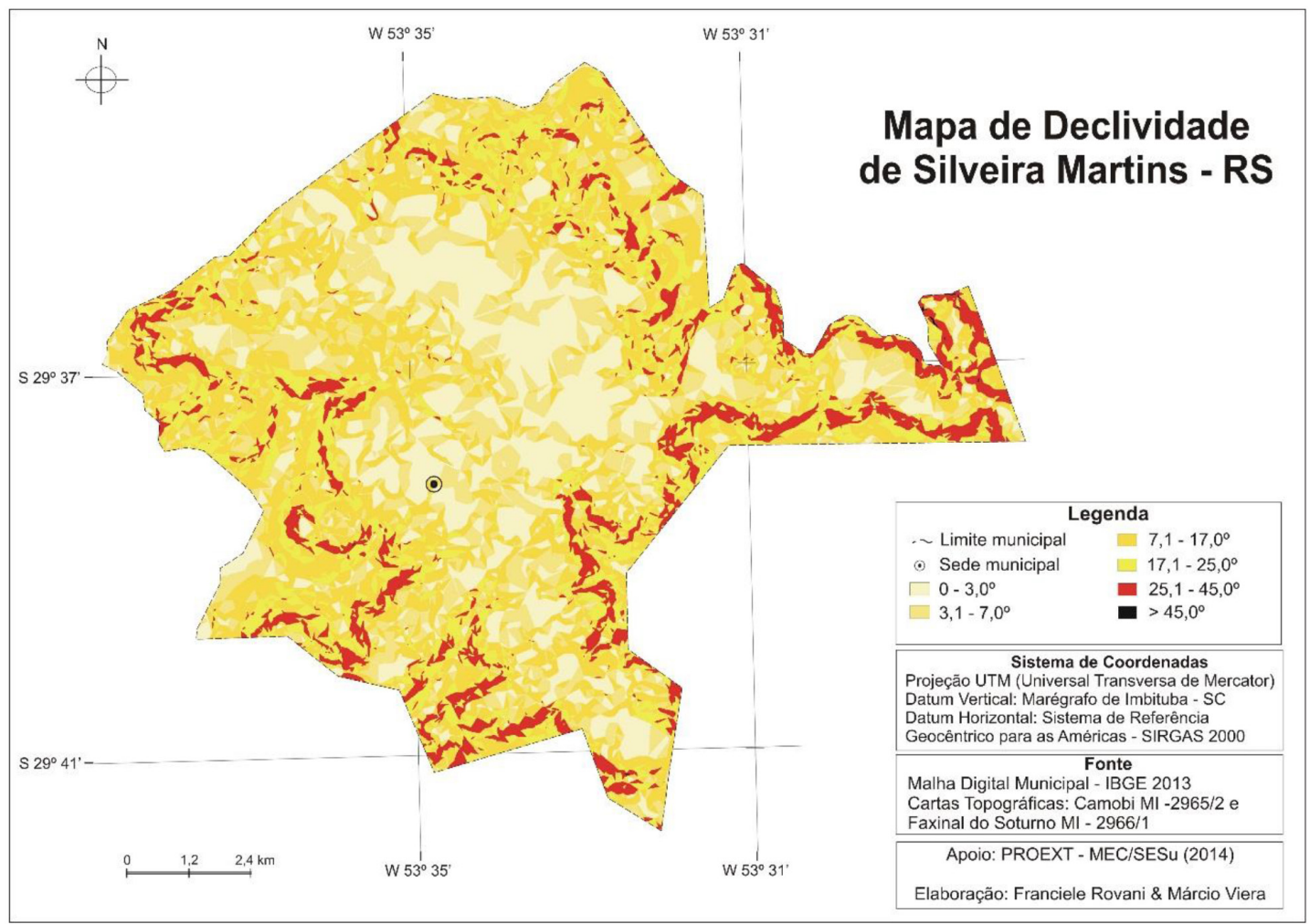

Figura 2. Mapa de declividade de Silveira Martins - RS.

Figure 2. Slope map of Silveira Martins - RS. 
(10,2\% do município), conforme a Lei 12.651 de 25 de maio de 2012 (Brasil, 2012), é considerada de uso restrito.

Em áreas consideradas de uso restrito, segundo o artigo 11 da Lei 12.651 (Brasil, 2012), serão permitidos o manejo florestal sustentável e o exercício de atividades agrossilvipastoris, bem como a manutenção da infraestrutura física associada ao desenvolvimento das atividades, observadas boas práticas agronômicas,

Tabela 2. Classes de declividade do município de Silveira Martins.

Table 2. Slope range of Silveira Martins.

\begin{tabular}{|cccc} 
Classes & Área (ha) & $\%$ & $\begin{array}{c}\text { Peso da } \\
\text { vulnerabilidade }\end{array}$ \\
\hline $0-3,0^{\circ}$ & $2.493,7$ & 21,1 & 1,0 \\
\hline $3,1-7,0^{\circ}$ & $2.208,7$ & 18,6 & 1,4 \\
\hline $7,1-17,0^{\circ}$ & $3.846,7$ & 32,5 & 1,8 \\
\hline $17,1-25,0^{\circ}$ & $2.079,6$ & 17,6 & 2,2 \\
\hline $25,1-45,0^{\circ}$ & $1.210,6$ & 10,2 & 2,6 \\
\hline $45,0^{\circ}$ & 2,8 & 0,02 & 3,0 \\
\hline Total & $11.842,3$ & 100,0 & - \\
\hline
\end{tabular}

sendo vedada a conversão de novas áreas, excetuadas as hipóteses de utilidade pública e interesse social.

Com base na lei supracitada, considerou-se que as áreas com declividade maior que $25^{\circ}$ e $45^{\circ}$ receberiam os pesos de vulnerabilidade característica de solos instáveis. Onde prevalecem os processos erosivos (Tabela 2). Declividade acentuada relacionada com o tipo de uso de solo favorece o escoamento superficial e a erosão laminar (Santos \& Sobreira, 2008a). Áreas com declividades entre $17^{\circ}$ e $25^{\circ}$, mesmo não sendo consideradas de uso restrito, com base na lei, apresentam restrições de mecanização das atividades agrícolas realizadas. Essas áreas apresentam maior potencial produtivo com a introdução de espécies silvícolas (Rovani et al., 2015).

O mapa de geologia pode ser observado na Figura 3. O mapa apresenta as diferentes formações geológicas que constituem a crosta terrestre em camadas sobrepostas. Verifica-se a presença de quatro classes geológicas, tendo a formação Serra Geral como a mais representativa do território (49,7\%), seguida pela formação Rio do Rastro $(32,4 \%)$, Botucatu $(11,7 \%)$ e Rosário do Sul $(6,2 \%)$.

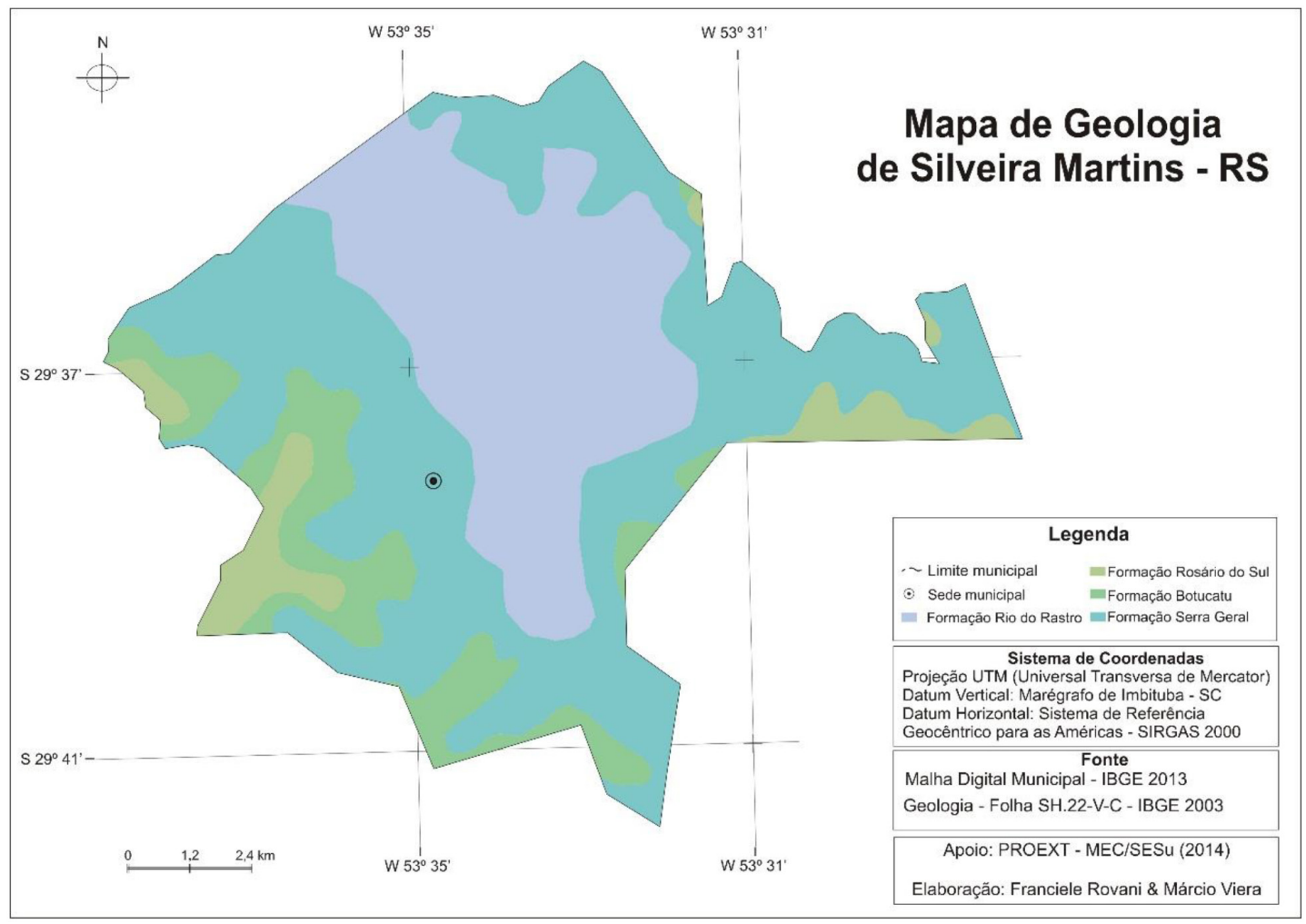

Figura 3. Mapa de geologia de Silveira Martins - RS.

Figure 3. Geology map of Silveira Martins - RS. 
As classes receberam escalas de vulnerabilidade de $1,2,1,7,2,5$ e 2,8, respectivamente, para as formações geológicas Serra Geral, Rio do Rastro, Rosário do Sul e Botucatu. A formação Serra Geral recebeu a menor escala de vulnerabilidade, pois segundo Rovani et al. (2015), caracteriza-se pela maior estabilidade com relação à perda natural de solo. Segundo os autores, as rochas que a constituem apresentam maior grau de coesão quando comparadas aos arenitos, aos xistos, aos siltítos, de menor grau de coesão. Entretanto, a formação Botucatu, formada predominantemente por arenitos, recebeu maior valor de vulnerabilidade entre todas as classes geológicas.

A formação Rio do Rastro foi originada na era Paleozóica, durante o período Permiano (entre 250 e 295 milhões de anos) (IBGE, 2003a). As formações Rosário do Sul, Botucatu e Serra Geral foram originadas na era Mesozóica, durante os períodos Triássico (entre 203 e 250 milhões de anos), Jurássico (entre 135 e 203 milhões de anos) e Cretáceo (entre 65 e 135 milhões de anos), respectivamente (IBGE, 2003a).
O mapa de geomorfologia pode ser observado na Figura 4. O mapa representa as diferentes formas do relevo do município de Silveira Martins. Verifica-se a presença de três classes geomorfológicas, tendo o Rebordo do Planalto como mais representativo do território (59,2\%), seguido pelo Planalto dos Campos Gerais $(39,2 \%)$ e Depressão do Rio Jacuí (1,6\%).

O Rebordo do Planalto caracteriza-se por ser área de transição entre o Planalto e a Depressão, apresentando relevo com elevada declividade (na escala de vulnerabilidade recebeu peso 2,5). O Planalto é formado por rochas basálticas decorrentes de um grande derrame de lavas, ocorrido na era Mesozóica (na escala de vulnerabilidade recebeu peso 1,5). Entretanto, a Depressão Central é formada por rochas sedimentares em áreas de baixa altitude (na escala de vulnerabilidade recebeu peso 2,0 ).

De acordo com o mapa de solos foram identificados três classes de solos predominantes no município de Silveira Martins (Figura 5). O Neossolo Regolítico Eutrófico (65,2\% do território municipal), o Argissolo Bruno Acinzentado Aluminíco (22,6\%) e o Argissolo

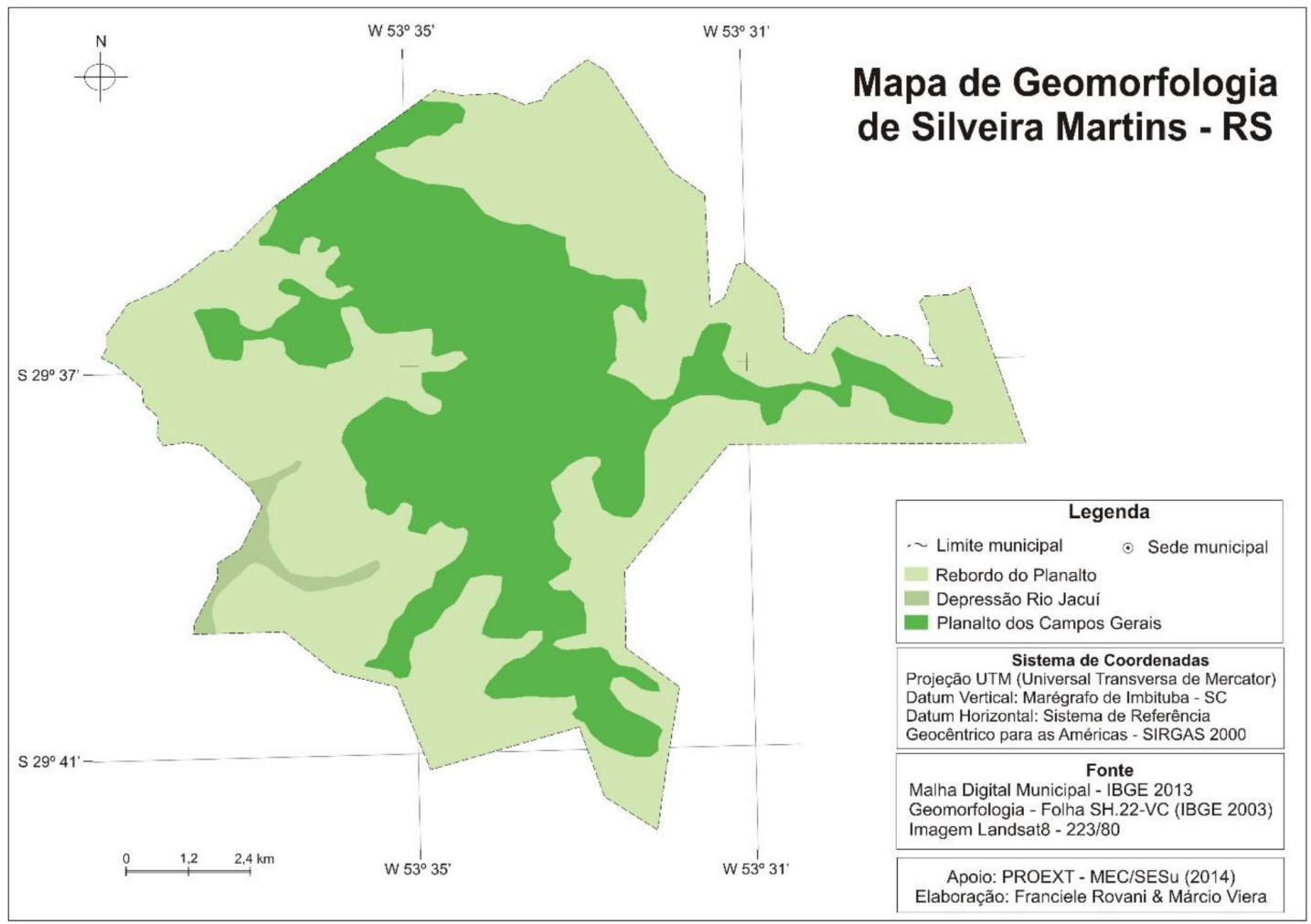

Figura 4. Mapa de geomorfologia de Silveira Martins - RS.

Figure 4. Geomorphology map Silveira Martins - RS. 


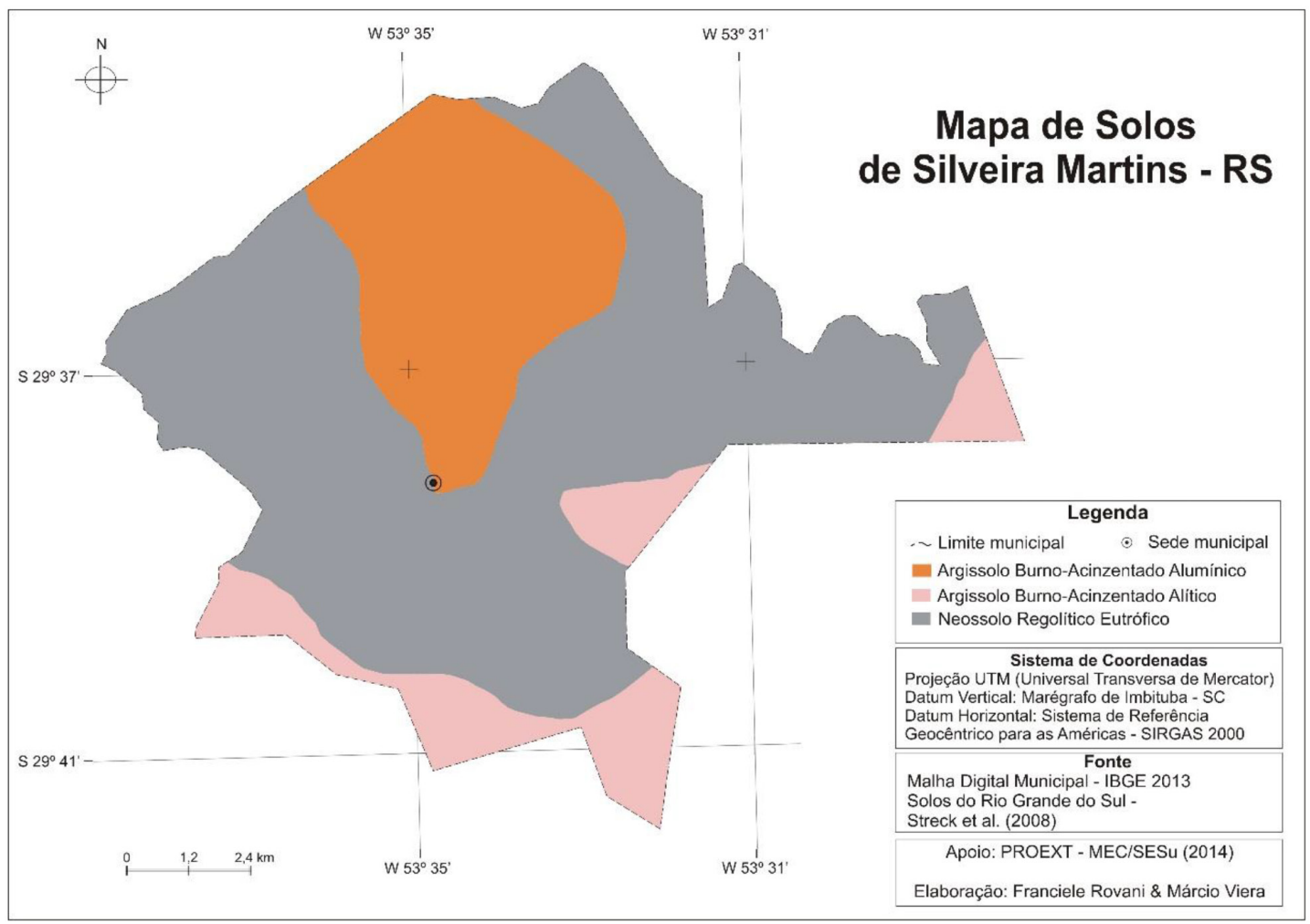

Figura 5. Mapa de solos de Silveira Martins - RS.

Figure 5. Soil map of Silveira Martins - RS.

Bruno Acinzentado Alítico (12,2\%), conforme Streck et al. (2008). Para o grau de vulnerabilidade dos Argissolos foi atribuído peso 2,0 e peso 3,0 para o Neossolo. Os argissolos são mais propícios para o cultivo agrícola, pois são solos mais profundos e localizados em áreas com menor declividade. Entretanto, os Neossolos Regolíticos possuem baixa aptidão agrícola. Isso deve-se ao fato da pequena profundidade efetiva e de estarem presentes, principalmente, em área com declividades acentuadas.

Os Neossolos compreendem solos constituídos por material mineral ou por material orgânico pouco espesso, pois são solos novos, pouco desenvolvidos a partir dos mais diversos tipos de rochas (EMBRAPA, 2006; Streck et al., 2008). Os argissolos são caracterizados pela presença de horizonte diagnóstico B textural, apresentando acúmulo de argila em profundidade devido à mobilização e perda de argila da parte mais superficial do solo (EMBRAPA, 2006). Apresentam frequentemente, mas não exclusivamente, baixa atividade da argila (CTC), podendo ser alíticos (altos teores de alumínio), distróficos (baixa saturação de bases) ou eutróficos (alta saturação de bases), sendo normalmente ácidos.

O mapa de vulnerabilidade natural à perda do solo (Figura 6) é resultante da integração das informações referentes aos valores de estabilidade/vulnerabilidade dos solos, da geomorfologia, da geologia e da declividade do terreno com base nas Unidades Territoriais Básicas (UTBs). As unidades que apresentaram valores entre 1,0 a 1,3 foram definidas como estáveis, as que apresentaram valores de 1,4 a 1,7 foram classificadas de moderadamente estável. Os valores no intervalo de 1,8 a 2,2 definiram a classe de medianamente estável/vulnerável, os valores entre 2,3 a 2,6 determinaram a classe de moderadamente vulnerável e, por fim, as unidades com valores entre 2,7 a 3,0 foram classificadas de vulneráveis.

Identificou-se a presença das cinco classes de estabilidade/vulnerabilidade, variando desde a classe estável até a classe vulnerável, com predomínio da classe medianamente estável/vulnerável. As áreas mais estáveis (classe estável e moderadamente estável) 


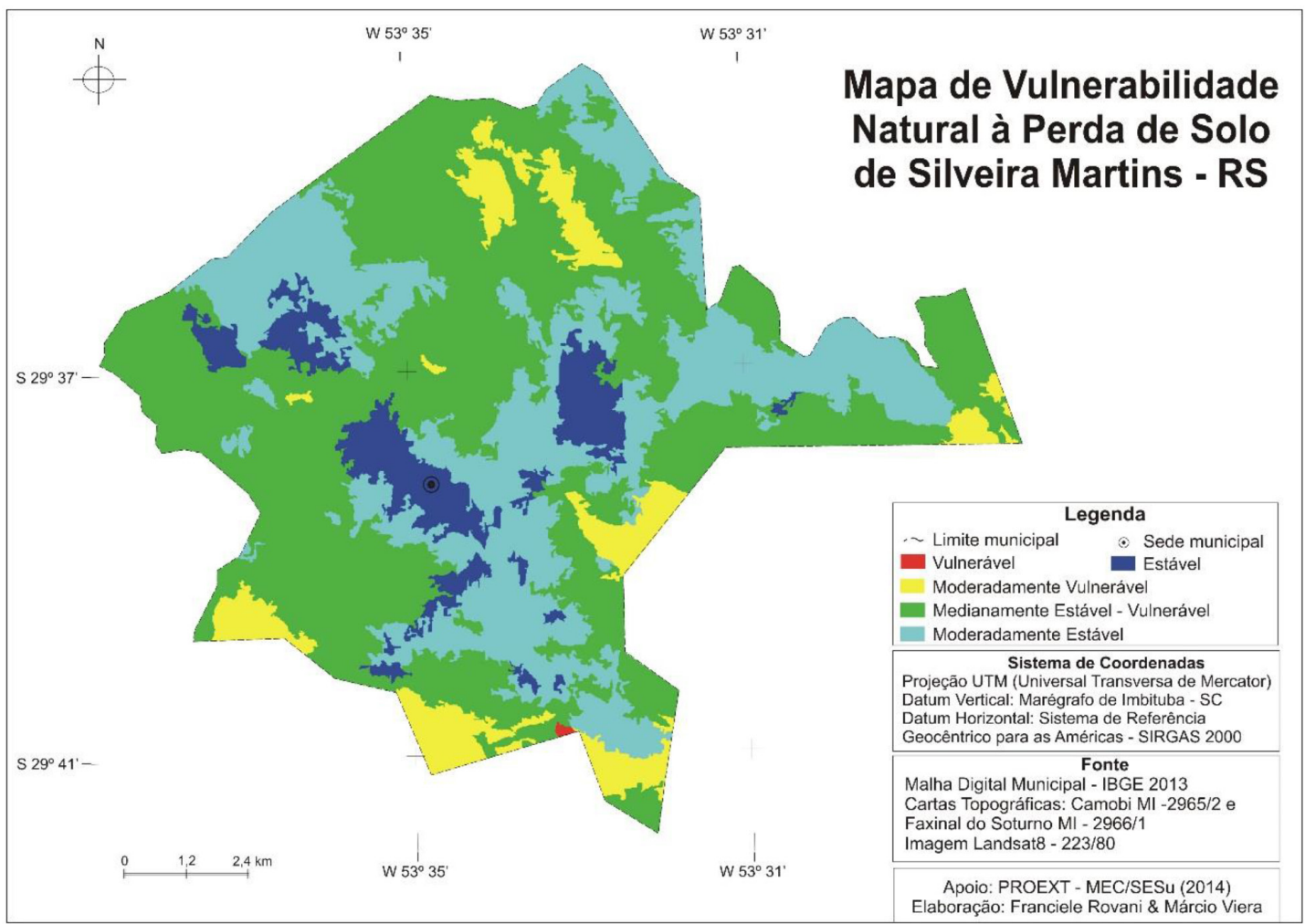

Figura 6. Mapa da Vulnerabilidade Natural à Perda de Solo de Silveira Martins.

Figure 6. Vulnerability of natural soil loss map of Silveira Martins.

à perda de solo representam as áreas relativamente homogêneas com relação às características de solo, geologia, geomorfologia e inclinação do relevo, totalizando 38,08\% da área municipal. Estão situadas principalmente nas áreas com menor declividade do relevo e com formação geológica e geomorfológica mais estável, favorecendo assim a pedogênese.

As áreas identificadas como mediamente estável/vulnerável, em maior proporção (53,67\%), estão na transição entre as unidades mais estáveis e as mais vulneráveis, sendo encontradas na maior parte territorial. Essas áreas apresentam um equilíbrio entre os processos de pedogênese e morfogênese (Mesquita et al., 2010; Rovani et al., 2015). As áreas classificadas como moderadamente vulnerável e vulnerável (8,25\% do total), correspondem a lugares do relevo com inclinações elevadas $\left(>25^{\circ}\right)$ e com formação geológica e geomorfológica menos estáveis. Essas áreas requerem maiores cuidados, pois nelas predominam os processos de morfogênese, modificadores do relevo (Rovani et al., 2015). Dessa forma, sugere-se especial atenção em relação ao meio natural e aos agentes que o influenciam, visando boas práticas sociais associadas às políticas ambientais no processo de tomada de decisões econômicas, possibilitando a valorização e proteção do meio natural.

\section{CONCLUSÕES}

Os avanços das ciências, das técnicas e dos métodos de análise, bem como a preocupação com as questões ambientais que relacionassem a sociedade e a natureza, permitiram o desenvolvimento de mapeamentos cartográficos detalhados do meio ambiente, principalmente aqueles relacionados ao ordenamento territorial dos municípios. Além disso, permite, a partir de seu produto final, o mapa síntese, propor ações de planejamento e gestão ambiental a serem implantadas pelos setores públicos e privados de acordo com a realidade de cada paisagem.

Identificou-se unidades consideradas estáveis, com predomínio dos processos formadores do solo, e unidades moderadamente vulneráveis, prevalecendo 
os processos erosivos. Essas unidades são importantes para indicar as melhores práticas de uso e ocupação da terra, com menor impacto ao ambiente.

\section{STATUS DA SUBMISSÃO}

Recebido: 9 dez., 2014

Aceito: 6 Ago., 2015

\section{AUTOR(ES) PARA CORRESPONDÊNCIA}

\section{Márcio Viera}

Departamento Multidisciplinar, Universidade

Federal de Santa Maria - UFSM, Francisco

Guerino, 407, CEP 97195-000, Silveira Martins,

RS, Brasil

e-mail: marcio.viera@ufsm.br

\section{APOIO FINANCEIRO}

PROEXT - MEC/SESu - 2014.

\section{REFERENCIAS}

Becker BK, Egler CAG. Detalhamento da metodologia para execução do zoneamento ecológico econômico pelos estados da Amazônia Legal. Brasília: SAE:MMA; 1996.

Brasil. Presidência da República. Lei $n^{\circ} 12.651$ de 25 de maio de 2012. Institui o Código Florestal Brasileiro. Dispõe sobre a proteção da vegetação nativa; altera as Leis nos 6.938, de 31 de agosto de 1981, 9.393, de 19 de dezembro de 1996, e 11.428, de 22 de dezembro de 2006; revoga as Leis nos 4.771, de 15 de setembro de 1965, e 7.754, de 14 de abril de 1989, e a Medida Provisória no 2.166-67, de 24 de agosto de 2001; e dá outras providências [online]. Diário Oficial da República Federativa do Brasil, Brasília, DF (2012 maio). [citado em 2014 jun. 07]. Disponível em: http://www.planalto.gov.br/ccivil_03/_ato2011-2014/2012/ lei/l12651.htm

Campagnani S, Santos UP. Programa de Zoneamento Ecológico-Econômico do estado do Rio de Janeiro. Projeto II: Zoneamento Ecológico-Econômico do Médio Vale do Paraíba. Rio de Janeiro: IEF: SEMA: CARTOGEO: NCE :UFRJ; 1998.

Crepani E, Medeiros JS, Azevedo LG, Hernandez P Fo, Florenzano TG, Duarte V. Curso de sensoriamento remoto aplicado ao zoneamento ecológico-econômico. São José dos Campos: INPE; 1996.

Crepani E, Medeiros JS, Azevedo LG, Hernandez P Fo, Florenzano TG, Duarte V. Zoneamento EcológicoEconômico. In: Florenzano TG, editor. Geomorfologia: conceitos e tecnologias atuais. São Paulo: Oficina de Textos; 2008. p. 285-318.

Empresa Brasileira de Pesquisa Agropecuária - EMBRAPA. Sistema brasileiro de classificação de solos. 2. ed. Rio de Janeiro: Embrapa Solos; 2006.

Hasenack $\mathrm{H}$, Weber E. Base cartográfica vetorial contínua do Rio Grande do Sul [CD-ROM]. Porto Alegre: UFRGS - Centro de Ecologia; 2010. Série Geoprocessamento. Escala 1:50000. 1 CD-ROM.

Instituto Brasileiro de Geografia e Estatística - IBGE. Geologia. Santa Maria SH.22-V-C [online]. Rio de Janeiro: IBGE; 2003a. [citado em 2014 jul. 17]. 1 mapa. Escala: 1/250000. Disponível em: ftp://geoftp.ibge.gov. br/mapas_tematicos/geologia/cartas_escala_250mil/ sh22vc_geol.pdf

Instituto Brasileiro de Geografia e Estatística - IBGE. Geomorfologia. Santa Maria SH.22-V-C [online]. Rio de Janeiro: IBGE; 2003b. [citado em 2014 jul. 17]. 1 mapa. Escala: 1/250000. Disponível em: ftp://geoftp.ibge.gov.br/ mapas_tematicos/geomorfologia/cartas_escala_250mil/ sh22vc_geom.pdfsg22yd_zc_geom.pdf

Instituto Brasileiro de Geografia e Estatística - IBGE. Censo agropecuário. Tabelas [online]. Rio de Janeiro: IBGE; 2006. [citado em 2014 jul. 17]. Disponível em: http://www.ibge.gov.br/home/estatistica/economia/ agropecuaria/censoagro/1995_1996/43/

Instituto Brasileiro de Geografia e Estatística - IBGE. Censo demográfico. Banco de dados agregados. Rio de Janeiro: IBGE; 2014. [citado em 2014 jul. 17]. Disponível em: http://www.sidra.ibge.gov.br/bda/tabela/protabl. asp? $\mathrm{c}=202 \& \mathrm{z}=\mathrm{t} \& \mathrm{o}=3 \& \mathrm{i}=\mathrm{P}$

Lima FR, Martinelli M. As unidades ecodinâmicas na Cartografia Ambiental de Síntese. In: Anais do I Simpósio de Pós-Graduação em Geografia do Estado De São Paulo; 2008; Rio Claro. Rio Claro: UNESP; 2008. [citado em 2014 jul. 17]. Disponível em: http://www.rc.unesp.br/ igce/simpgeo/440-448fredy.pdf

Lima LPZ, Louzada J, Carvalho LMT, Scolforo JRS. Análise da vulnerabilidade natural para implantação de unidades de conservação na microrregião da Serra de Carrancas, MG. Cerne 2011; 17(2): 151-159. http://dx.doi. org/10.1590/S0104-77602011000200002.

Mesquita C, Assis AQS, Souza RM. Vulnerabilidade natural à perda de solos da bacia hidrográfica do Rio Sagrado - Morretes/PR. Revista de Geografia 2010; 27(N. esp. 2): 249-264.

Pereira JR, Ferreira PA, Boas AAV, Oliveira ER, Cardoso RF. Gestão social dos territórios da cidadania: o zoneamento ecológico-econômico como instrumento de gestão do território noroeste de Minas Gerais. Cadernos EBAPE. BR 2011; 9(3): 724-747.

Rovani FFM, Cassol R, Wollmann CA, Simioni JPD. Análise da vulnerabilidade natural à perda de solo de 
Barão de Cotegipe, RS. Revista do Departamento de Geografia - USP 2015; 29(1): 264-282.

Rovani FFM, Sartori MGB, Cassol R. Zoneamento ecológicoeconômico de Barão de Cotegipe, RS: potencialidade para o ordenamento do território. Revista Brasileira de Cartografia 2014; 66(1): 137-151.

Santos CA, Sobreira FG. Análise morfométrica como subsídio ao zoneamento territorial: o caso das bacias do Córrego Carioca, Córrego do Bação e Ribeirão Carioca na região do Alto Rio das Velhas-MG. Revista Escola de Minas 2008a; 61(1): 77-85. http://dx.doi.org/10.1590/ S0370-44672008000100013.

Santos CA, Sobreira FG. Análise da fragilidade e vulnerabilidade natural dos terrenos aos processos erosivos como base para o ordenamento territorial: o caso das bacias do Córrego Carioca, Córrego do Bação e Ribeirão Carioca na região do alto Rio das Velhas-MG. Revista Brasileira de Geomorfologia 2008b; 9(1): 65-73.

Santos MRR, Ranieri VRL. Critérios para análise do zoneamento ambiental como instrumento de planejamento e ordenamento territorial. Ambiente \& Sociedade 2013; 26(4): 43-62. http://dx.doi.org/10.1590/S1414753X2013000400004

Simões M, Becker B, Egler C, Miranda M, Orleans e Bragança PC, Santos UP et al. Metodologia para elaboração do Zoneamento Ecológico-Econômico em áreas com grande influência antrópica. Rio de Janeiro: Embrapa Solos; 1999. [citado em 2014 jul. 17]. Disponível em: http://www.laget. igeo.ufrj.br/egler/pdf/maggie.pdf

Streck EV, Kämpf N, Dalmolin RSD, Klant E, Nascimento PC, Scheneider P. Solos do Rio Grande do Sul. 2. ed. Porto Alegre: EMATER/RS; 2008.

Tricart J. Ecodinâmica. Rio de Janeiro: IBGE; 1977. 